\title{
A RETROSPECTIVE ANALYSIS OF PEDIATRIC FACIAL FRACTURES
}

\author{
Gaafar N. El Halawani* and Hala R. Ragab ${ }^{* *}$
}

\begin{abstract}
Introduction: Pediatric fractures despite being less common than adults is very critical as it can affect growth in the fractured areas

Objectives: This study aimed to detect the incidence, pattern of fracture and treatment modalities in the last 3 years in patients with age ranging from 0-18 years treated at the oral and maxillofacial surgery department, Alexandria University.

Materials and Methods: This study was conducted on patients with age below 18 years admitted to the outpatient clinic of the oral and maxillofacial department, Alexandria university, From January 2016 to December 2018.

Results: The mean age was 12 years, $78.7 \%$ were males while $21.27 \%$ were females. Causes of fracture were road traffic accidents in $46.8 \%$ of patients, falls in $38.3 \%$, and assault in $14.89 \%$. Regarding mandibular fractures, parasymphyseal fractures were $15.25 \%$, condylar fractures were $13 \%$, symphyseal fractures were $11.86 \%$, angle fractures were $11.86 \%$ and body fractures were $10.16 \%$. Regarding midface fractures, zygomatic fractures were $15.25 \%$, nasal fractures were $10.16 \%$, orbital blow out fractures were $6.78 \%$ and le fort fractures were $5 \%$. Regarding treatment, $69.17 \%$ of the patients were treated by open reduction and fixation, closed reduction accounted for $21.18 \%$ and $9.57 \%$ needed observation only.
\end{abstract}

Conclusions: The incidence of pediatric facial fractures is ascending with RTAs and falls as the leading causes. Regarding mandibular fractures, parasymphyseal and condylar fractures were the most frequent; whereas zygomatic and nasal fractures were the most common midface fractures. In addition, open reduction was the highest treatment modatality in frequency.

KEYWORDS: Pediatric, Facial fractures, Incidence.

* Lecturer at Oral and Maxillofacial Surgery Department,Faculty of Dentistry,Alexandria University.(Correspondent)

** Assistant Professor of Oral and Maxillofacial Surgery, Department of Oral and Maxillofacial Surgery, Faculty of Dentistry, Alexandria University. 


\section{INTRODUCTION}

Fracture in children and adolescents are uncommon and account only for 1-15\%.Moreover, the pattern and clinical features differs when compared to adults. This can be attributed to multiple factors including the lesser bone density, deciduous crown shape, lack of pneumatization of the paranasal sinuses, immature facial skeleton, the prominent buccal fat pad and the presence of unerupted or partially erupted teeth in pediatrics. ${ }^{1,2}$

Pediatric fractures are divided into three categories: preschool age from 0-5 years, mixed dentition age from 6-12 years and adolescent age from 13-18 years. Moreover, there is a directly proportional relationship between age and the frequency of fracture. ${ }^{3}$ Young children are under close parental supervision which decreases gradually as the child grows up leading to a higher frequency of trauma. In addition, Children at birth have a retruded facial position leading to a lower incidence of facial fractures in children lesser than 5 years which gradually increases as the face moves downward and forward with facial growth. ${ }^{3-5}$

Etiology of fracture in pediatrics ranges from fall, road traffic accidents, assaults and others. ${ }^{2-5}$ The incidence of the different etiologies varies from one country to the other due to the differences in environmental, socioeconomical and cultural aspects. ${ }^{2}$ In addition, children under the age of 5 have an underdeveloped sensory and motor skills which leads to increase frequency of falls. On the other side, adolescents shows a higher frequency of road traffic accidents. ${ }^{6}$

The purpose of our study was to detect the incidence, the type of fracture and treatment modalities in the last 3 years in patients with age ranging from 0-18 years treated at the oral and maxillofacial surgery department, Alexandria University.

\section{PATIENTS AND METHODS}

The present study is a retrospective analysis conducted on pediatric patients admitted to the outpatient clinic of the oral and maxillofacial department, Alexandria University, From January
2016 to December 2018. Pediatric patients with age ranging from 0-18 years were included in the study.

The data collected included the age, gender, etiology, type of fracture and treatment. Regarding age, the patients were divided into 3 groups according to age: group 1(0-5 years, preschool), group 2 (612 years, mixed dentition stage) and group 3 (1318 years adolescent age). Thorough history taking, clinical and radiographic examination was done for all patients. The type of fracture was detected based on preoperative computed tomography x rays (CT).

\section{RESULTS}

\section{Age and gender (Table 1)}

During the studied period a total of 246 patients were operated, out of which 94 (38.21\%) were 18 years or younger with a mean age of 12 years. Moreover, the incidence of trauma increased with age: 14 patients in group 1(14.89\%), 18 in group $2(19.15 \%)$ and 62 in group 3(65.96\%). Regarding the gender 74 patients $(78.7 \%)$ were males while 20 $(21.27 \%)$ were females.

TABLE (1) Age distribution

\begin{tabular}{|l|l|}
\hline Age & Number(\%) \\
\hline $\mathbf{0 - 5}$ & $14(38)$ \\
\hline $\mathbf{6 - 1 2}$ & $18(19.15)$ \\
\hline $\mathbf{1 3 - 1 8}$ & $62(65.96)$ \\
\hline
\end{tabular}

\section{Etiology (Table 2)}

The causes of fracture fell under 3 categories. 44 patients were road traffic accidents RTA (46.8\%), 36 were falls $(38.3 \%)$, and 14 were assaults $(14.89 \%)$.

In group 1, 9 patients were falls $(64.28 \%), 4$ were RTA $(28.57 \%)$ and 1 was assault $(7.14 \%)$. In group 2, 10 patient were RTA (55.55\%), 5 were falls $(27.77 \%)$ and 3 were assaults $(16.66 \%)$. In group 3, 30 patients were RTA (48.38\%), 22 were falls $(35.48 \%)$ and 10 were assaults $(16.13 \%)$. 
TABLE (2) Etiology of fracture

\begin{tabular}{|l|l|l|l|l|}
\hline Cause & Group 1 & Group 2 & Group 3 & Number(\%) \\
\hline RTA & 4 & 10 & 30 & $44(46.8)$ \\
\hline Falls & 9 & 5 & 22 & $36(38.3)$ \\
\hline Assault & 1 & 3 & 10 & $14(14.89)$ \\
\hline Total & 14 & 18 & 62 & $94(100)$ \\
\hline
\end{tabular}

\section{Type of fracture (Table 3 )}

118 fractures were analyzed in 94 studied patients. Mandibular fractures were more common with 74 fractures $(62.71 \%)$, while midface fractures were $44(37.28 \%)$.

Regarding mandibular fractures, parasymphyseal fractures were the most common with 18 fractures $(15.25 \%)$. Condylar fractures were $16(13 \%)$, symphyseal fractures were $14(11.86 \%)$, angle fractures were $14(11.86 \%)$ and body fractures were 12 (10.16).

TABLE (3) Type of fracture

\begin{tabular}{|l|l|}
\hline Type of fracture & Number(\%) \\
\hline Parasymphyseal & $18(15.25)$ \\
\hline Condylar & $16(13 \%)$ \\
\hline Symphyseal & $14(11.86)$ \\
\hline Angle & $14(11.86)$ \\
\hline Body & $12(10.16)$ \\
\hline Zygomatic & $18(15.25)$ \\
\hline Nasal & $12(10.16)$ \\
\hline Orbital & $8(6.78)$ \\
\hline Le fort & $6(5)$ \\
\hline
\end{tabular}

Regarding midface fractures, zygomatic fractures came at the top with 18 fractures (15.25\%). Nasal fractures were $12(10.16 \%)$, orbital blow out fractures were $8(6.78 \%)$ and le fort fractures were $6(5 \%)$.

\section{Treatment (Table 4, Fig 1,2)}

Regarding treatment modalities, open reduction and internal fixation was the highest in frequency with 65 patients $(69.14 \%)$. Internal fixation was done using miniplates and resorbable plates. Whereas, closed reduction accounted for 20 patients $(21.18 \%)$ and 9 patients needed observation only $(9.57 \%)$.

TABLE (4) Treatment

\begin{tabular}{|l|l|}
\hline Treatment & Number(\%) \\
\hline Observation & $9(9.57)$ \\
\hline Closed reduction & $20(21.28)$ \\
\hline Open reduction & $65(69.14)$ \\
\hline
\end{tabular}

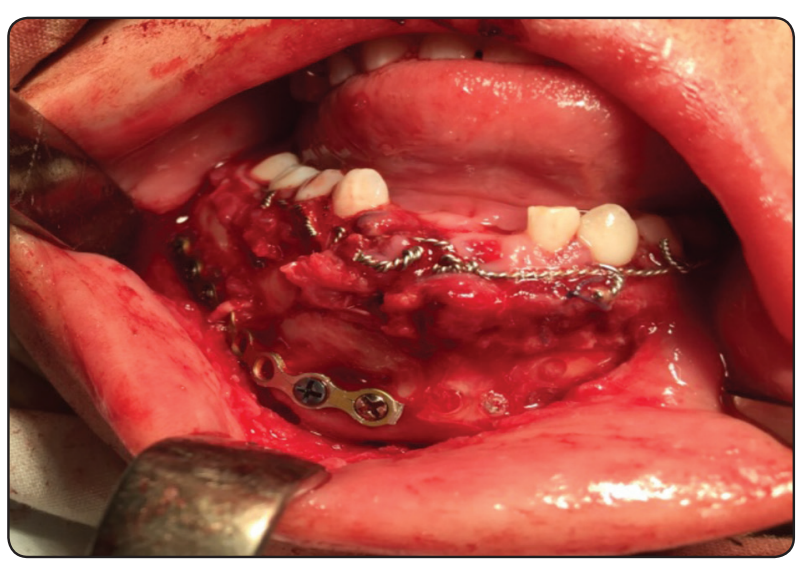

Fig. (1) Clinical photograph showing rigid fixation using miniplate. 


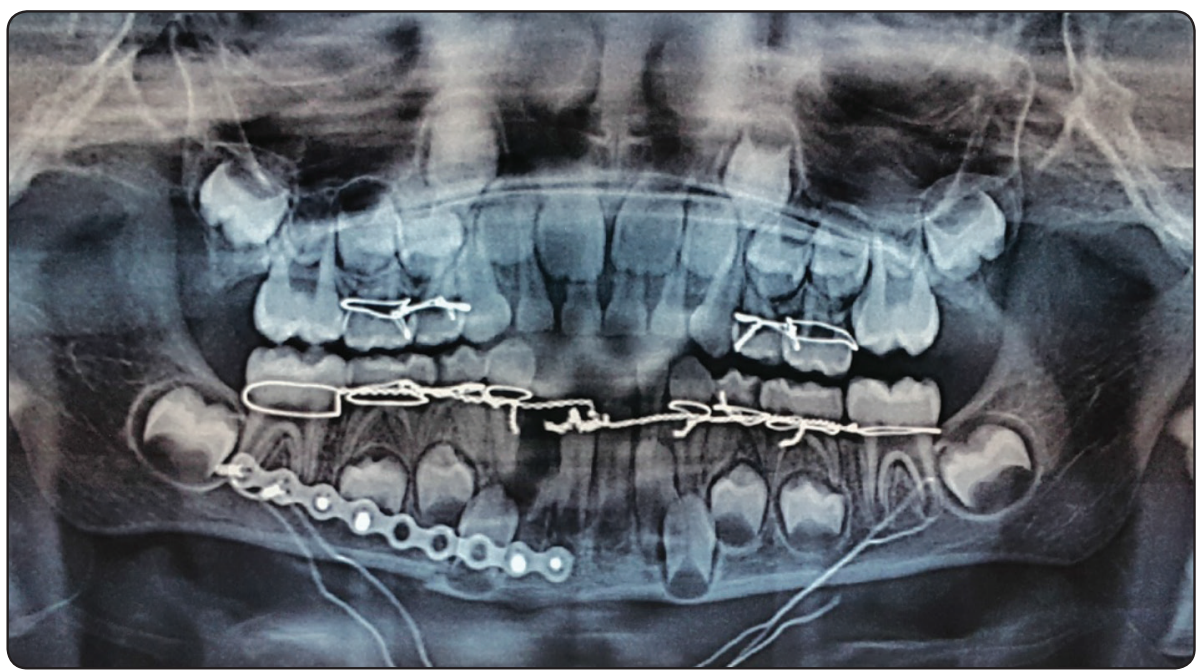

Fig (2) Postoperative panoramic radiograph showing rigid fixation using miniplates.

\section{DISCUSSION}

In this study pediatric facial trauma accounted for $38.21 \%$ of all facial traumas, this value is considered high when compared to other studies. Haug and foss $^{7}$; in their 25 year review; stated that the pediatric population sustains $1 \%$ to $14.7 \%$ of all facial fractures. This is also consistent with the 6 -year retrospective epidemiological study conducted by Subhashraj et $\mathrm{al}^{8}$ on a group of brazillian patients in 2007 , in which patients 20 years or less accounted for $11 \%$. However, a 3 year retrospective study conducted by Chrcanovic et $\mathrm{al}^{9}$ in 2010 found the incidence to be $20.32 \%$. Furthermore, Cardenas et $\mathrm{al}^{1}$; in their 10 year study in brazil in 2011; also revealed an incidence of $25.35 \%$. The last two studies are more consistent with our results.

Despite the higher incidence of pediatric facial fractures in our results, it is still lower than adults and increases with age with highest incidence in adolescence. This goes with most studies and is attributed to the cranium-face ratio in children which is $8: 1$, whereas for an adult it is $2: 1$, therefore in children the cranium is more subjected to trauma than the face. This ratio decreases gradually with facial growth and so does the incidence of facial fractures. In addition, younger children have retruded facial position and are under closer parenteral supervision which decreases the incidence of trauma. ${ }^{5-9}$
In contrast, González et $\mathrm{al}^{3}$ reported that the highest incidence of pediatric fractures were in children 5 years or less and the lowest in adolescence. In addition, Joshi et al ${ }^{10}$ stated that children 4-10 years old showed highest incidence of fractures and adolescents were the least.

The gender distribution showed males were more frequently affected than females, this matches most previous studies and is attributed to the higher activity of boys. However, Scariot and colleagues ${ }^{2}$ reported that the female incidence despite being lower than males is approximating the male values because girls are becoming more and more engaged in the same activities.

Regarding the etiology of fracture, road traffic accidents (RTA) was the highest in incidence followed by falls and assaults were the least. The etiology of varies based on differences in social, environmental and cultural factors; however most studies reported RTA and falls to be the main causes of pediatric fractures. Our results coincide with the study done by Khalifa et $\mathrm{a}^{11}$ in Egypt in which RTAs also showed highest incidence. In addition, Iida and Matsuya ${ }^{12}$ also reported an increase in RTAs in pediatrics while falls and assault remain steady.

In contrast, Scariot et $\mathrm{al}^{2}$, Gassner et $\mathrm{al}^{13}$, Haug and Foss ${ }^{7}$ and Qudah and Bataineh ${ }^{14}$; in their studies; 
reported that accidental falls were the highest in incidence and they attributed this to the fact that children aged 0 to 6 years have underdeveloped motor skills and coordination.

Furthermore, this study showed falls to be the highest in incidence in children aged 0 to 5 years; whereas, road traffic accidents were of highest frequency in children aged 6 to 12 years and 13 to 18 years. These results coincides with most studies ${ }^{3,11}$, ${ }^{12}$; However, it disagrees with Kim et $\mathrm{al}^{15}$ and joshi et $\mathrm{al}^{10}$ who stated that falls of highest in frequency in all age groups.

Mandibular fractures were the most encountered in this study $(62.71 \%)$. This agrees with previous reports which attributed this to the mobility and projection of the mandible. The incidence of mandibular fractures matches Khalifa et al ${ }^{11}$ who also reported a $67 \%$ incidence in their study in cairo. However, other studies reported lower incidence ranging from $40-57 \% .^{12,15}$

In this study parasymphyseal fractures comes on the top of mandibular fractures followed by condylar fractures. This disagrees with most studies $3,8,10,11$ in which condylar and angle fractures were higher in incidence than parasymphyseal fractures and can be related to the high frequency of road traffic accidents in this study.

Regarding midface, zygomatic fractures were the highest in incidence followed by nasal fractures. This comes in agreement with Cardenas et $\mathrm{al}^{1}$ and haug et $\mathrm{al}^{7}$; howevever, our results disagrees with the study of khalifa et $\mathrm{al}^{11}$ which reported le fort I fractures as the most common and that of Kim et al ${ }^{16}$ which stated that nasal fractures were the most encountered.

Regarding treatment modalities, open reduction and fixation was the highest in frequency. This coincides with $\mathrm{Kim}$ et $\mathrm{al}^{16}$ and Lida et $\mathrm{al}^{12}$ and disagrees with khalfa et $\mathrm{al}^{11}$ and Cardena et $\mathrm{al}^{1}$, who reported closed reduction as the most common treatment modality.

\section{CONCLUSION}

Our study concluded that the incidence of pediatric facial fractures is ascending with RTAs and falls as the leading causes. Regarding mandibular fractures, parasymphyseal and condylar fractures were the most frequent; whereas zygomatic and nasal fractures were the most common midface fractures. In addition, open reduction was the highest treatment modatality in frequency.

\section{RECOMMENDATIONS}

Preventive measures are recommended to minimize the risk of trauma in pediatric patients. Children shouldn't be seated in the front car seat and should be encouraged to wear protective gear like bicycle and motorcycle helmets. Pediatric car seats for younger children up are preferable as the conventional seat belts are ineffective in their situation.

\section{REFERENCES}

1. Muñante-Cárdenas JL, Olate S, Asprino L, de Albergaria Barbosa JR, de Moraes M, Moreira RW. Pattern and treatment of facial trauma in pediatric and adolescent patients.J Craniofac Surg. 2011;22(4):1251-5.

2. Scariot R, de Oliveira IA, Passeri LA, Rebellato NL, Müller PR. Maxillofacial injuries in a group of Brazilian subjects under 18 years of age. J Appl Oral Sci. 2009; 17(3): 195-198.

3. Collao-González C1, Carrasco-Labra A, Sung-Hsieh HH, Cortés-Araya J. Epidemiology of pediatric facial trauma in Chile: a retrospective study of 7,617 cases in 3 years. Med Oral Patol Oral Cir Bucal. 2014;19(2):e99-e105.

4. Eggensperger, NM, Hölzle, A \&lizuka, T. Pediatric Craniofacial Trauma. J Oral Maxillofac Surg. 2008;66(1):58-64.

5. Smartt JM, Low DW, Bartlett SP. The pediatric mandible: I. A primer on growth and development. Plast. Reconstr. Surg. 2005; 116(1): 14e-23e.

6. Girgis NF, Zanaty AW, El Agmy SS, Abd El Magid Abd El Khalek SH. Patterns of facial trauma in menoufia university hospital. Menoufia Med J 2017;30:1186-92. 
7. Haug RH, Foss J. Maxillofacial injuries in the pediatric patient. Oral Surg Oral Med Oral Pathol Oral Radiol Endod. 2000;90(2):126-34.

8. Subhashraj K, Nandakumar N, Ravindran C. Review of maxillofacial injuries in Chennai, India: a study of 2748 cases. Br J Oral Maxillofac Surg. 2007; 45(8):637-9.

9. Chrcanovic BR, Abreu MH, Freire-Maia B, Souza LN. Facial fractures in children and adolescents: a retrospective study of 3 years in a hospital in Belo Horizonte, Brazil. Dent Traumatol. 2010;26(3):262-70.

10. Joshi R. R. Khanal S, Rijal AS, Sagtani A, Maharjan S. Facial trauma in children and adolescents of Nepal. Med. Res. Chron., 2017, 4 (4), 387-394.

11. Khalifa GA, El-Kilani NS, Nasr TA. Clinical outcomes of Pediatric Maxillofacial Fractures Management in Three Hospital Series in Egypt. J Oral Maxillofac Surg Med Pathol. 2017;29(6):511-517.
12. Iida S, Matsuya T. Paediatric maxillofacial fractures: their aetiological characters and fracture patterns. J Craniomaxillofac Surg 2002;30(4):237-41

13. Gassner R, Tuli T, Hächl O, Moreira R, Ulmer H. Craniomaxillofacial trauma in children: a review of 3.385 cases with 6,060 injuries in 10years. J Oral Maxillofac Surg. 2004;62(4):399-407.

14. Qudah MA, Bataineh AB. A retrospective study of selected oral and maxillofacial fractures in a group of Jordanian children. Oral Surg Oral Med Oral Pathol Oral Radiol Endod. 2002;94(3):310-4.

15. Ferreira PC, Amarante JM, Silva PN, Rodrigues JM, Choupina MP, Silva AC. Retrospective study of 1251 maxillofacial fractures in children and adolescents. Plast Reconstr Surg 2005;115(6):1500-8.

16. Kim SH, Lee SH, Cho PD. Analysis of 809 facial bone fractures in a pediatric and adolescent population. Arch Plast Surg. 2012;39(6):606-11. 